\title{
History of domestic violence and health service use among mid-aged
}

\section{Australian women}

Deborah Loxton ${ }^{2}$, PhD, Margot Schofield ${ }^{1,2}$, PhD, \& Rafat Hussain ${ }^{1}$, PhD

${ }^{1}$ School of Health, University of New England, Australia

${ }^{2}$ Research Centre for Gender and Health, University of Newcastle, Australia 
History of domestic violence and health service use among mid-aged Australian women 


\begin{abstract}
Objectives: To examine associations between history of domestic violence and health service use among mid-aged Australian women, adjusting for physical and psychological health status and demographic factors.
\end{abstract}

Methods: Population-based cross-sectional postal survey (1996) of the Australian Longitudinal Study on Women's Health, known as Women's Health Australia. Of 28,000 women randomly selected, 14,100 (53.5\%), aged 45-50 years participated. Participants adequately represented the population of Australian mid-aged women. Logistic regressions were used to assess associations between domestic violence and health service use.

Results: After adjusting for demographic variables, multivariate analysis revealed associations between ever having experienced domestic violence and three or more consultations in the previous 12 months with a family doctor $(\mathrm{OR}=2.07,95 \% \mathrm{CI}=1.68$, 2.55), hospital doctor $(\mathrm{OR}=1.77,95 \% \mathrm{CI}=1.44,2.17)$, or specialist doctor $(\mathrm{OR}=1.54$, $95 \% \mathrm{CI}=1.35,1.75)$, or being hospitalised $(\mathrm{OR}=1.36,95 \% \mathrm{CI}=1.20,1.54)$. After adjusting for demographic variables and physical and psychological health status (measured for previous four weeks), these associations were attenuated: three or more consultations with family doctor $(\mathrm{OR}=1.36,95 \% \mathrm{CI}=1.09,1.70)$, hospital doctor $(\mathrm{OR}=1.16,95 \% \mathrm{CI}=$ $0.92,1.45)$, or specialist doctor $(\mathrm{OR}=1.14,95 \% \mathrm{CI}=0.98,1.32)$, and being hospitalised $(\mathrm{OR}=1.10,95 \% \mathrm{CI}=0.96,1.26)$.

Conclusions: Physical and psychological health status accounted for the associations between domestic violence and higher health service use, with the exception of general practitioner consultations, which remained associated with domestic violence.

Implications: Physical health status only partially explains the increased health service use associated with domestic violence, while both physical and psychological health status explained higher usage of specialist and hospital services. It seems likely that women who have experienced domestic violence may be seeking consultations from family doctors for reasons additional to health status. 


\section{Introduction}

Women who have experienced domestic violence tend to be over-represented in clinic-based samples. For example, lifetime prevalence of domestic violence was $20 \%$ in a nationally representative survey in the US, ${ }^{1}$ compared to $26 \%$ for hospitalised women. ${ }^{2}$ Furthermore, $51 \%$ of women attending an outpatient clinic, ${ }^{3}$ reported having experienced domestic violence. In studies done using data from hospital emergency department in the US lifetime prevalence of domestic violence has varied from $33 \%$ to $54 \% .^{4-5}$ A study conducted in the United Kingdom revealed a lifetime prevalence of $41 \%$ for women attending their general practitioner; ${ }^{6}$ while in an Irish study, 39\% of women attending their general practitioner had ever experienced physical violence from a partner ${ }^{7}$.

Some Australian studies show a similar difference in prevalence between nationally representative and clinical populations. For instance, a nationally representative populationbased study found that $2.6 \%$ of women currently living in intimate relationships had experienced domestic violence, ${ }^{8}$ while $22 \%$ of women attending their general practitioner had experienced domestic violence in the last 12 months. ${ }^{9}$ However, some Australian clinicbased studies have revealed lifetime prevalence rates for domestic violence that were lower than those found in overseas studies, similar to the $23 \%$ lifetime prevalence of domestic violence found among women who took part in a national random sample, ${ }^{8}$ and lower than the lifetime prevalence of $28.5 \%$ found among a random sample of mid-aged women. ${ }^{10}$ For example, $23.3 \%$ of women attending their general practitioners; ${ }^{11} 23.1 \%$ of women attending a hospital emergency department in Sydney; ${ }^{12}$ and $23.9 \%$ of women attending an emergency department in Brisbane had ever experienced partner perpetrated physical abuse. ${ }^{13}$

Domestic violence has been associated with increased health service use. Women who have experienced domestic violence claim more per annum in medical insurance, ${ }^{14}$ undertake 
more visits to emergency departments, ${ }^{15}$ and are more likely to be hospitalised ${ }^{16}$ than women who have not experienced domestic violence. Similarly, domestic violence has been associated with increased general practitioner consultations ${ }^{17}$ and outpatient and clinic visits. $^{15,17}$

Domestic violence has also been associated with impaired general health, ${ }^{18,19}$ an increased number of symptoms and diagnoses, ${ }^{20}$ and increased persistent health problems. ${ }^{19-21}$ While explanations vary for the relatively poor physical health of women who have lived in a violent relationship, some researchers have suggested that increased symptoms are a physical manifestation of ongoing psychological stress. ${ }^{22}$ Therefore, it is possible that some women are seeking consultations for medical problems that may be better treated with psychological interventions. Furthermore, other researchers have suggested that the relationship between domestic violence and increased health service use occurs because these environments are safe and/or supportive. ${ }^{14,16}$

Past research has been inconclusive about the extent to which poorer physical health and psychological wellbeing account for the documented relationship between past domestic violence and greater health service use. For instance, injuries and illnesses caused by domestic abuse accounted for a considerable proportion of emergency department and clinic visits made by women who had experienced domestic violence. ${ }^{15}$ By contrast, in a sample of women with depression, domestic abuse was associated with increased health service use for physical problems after controlling for the severity of illnesses. ${ }^{18}$ However, information from population based Australian samples with regard to the relationship between domestic violence and health service use is scarce. No population-based research was found that controlled for health status when investigating the relationship between domestic violence and health service use. The current paper, thus, aims to determine the relationship between 
domestic violence and health service use, after adjusting for physical and psychological health status and demographic variables.

\section{Methods}

This study utilised data collected for the first survey of the mid-aged sample of the Australian Longitudinal Study on Women's Health, also called Women’s Health Australia (WHA). WHA is a longitudinal survey of the health and well-being of three cohorts of Australian women, and has been described in detail elsewhere. ${ }^{23,24}$ The project uses mailed surveys to collect self-report data on health and related variables from three cohorts of Australian women, who were aged 18-23 years ("young"), 45-50 years ("mid-age") and 7075 years ("older") when data collection began in 1996. Over 40,000 women were recruited on a random basis from the Australian population, with the national health insurance database (Medicare, managed by the Health Insurance Commission) as the sampling frame and intentional over-sampling of women living in rural and remote areas. The project is designed to run for at least twenty years, with the overall goal being to conduct a series of interlocking data analyses in order to develop an understanding of factors that affect the

health and well-being of women, in order to inform Australian government health policy. ${ }^{23}$ The WHA project surveys were approved by the University of Newcastle Human Research Ethics Committee.

\section{Participants}

Twenty eight thousand mid-aged women were randomly selected from the Medicare database by the Health Insurance Commission and invited by mail to participate in the WHA project. Of these, 14,100 women, aged 45-50, consented to take part. The response rate was estimated to be $53.5 \%$. The sample was found to adequately represent the general population of Australian mid-aged women, although women who were married or living in a de facto relationship, and women with a university degree were over-represented, when compared to 
census data. ${ }^{24}$ Details of the recruiting process and sample composition are available elsewhere. $^{23,24}$

\section{Measures}

Domestic violence. History of domestic violence was assessed by asking the participants if they had ever been in a violent relationship with a partner/spouse (yes/no).

Consultations. The health care service use scale was a modified form of that used by the Australian Bureau of Statistics ${ }^{25}$ and asked respondents to indicate how many times in the previous year ('none’; ‘once or twice’; ‘three or four times’; 'five or six times'; 'seven or more times') they had consulted with each of various health professionals (family doctor; hospital doctor; specialist doctor). The response categories were collapsed due to low frequencies in higher response categories, resulting in three categories: no consultations; one or two consultations; and three or more consultations.

Recent hospital admission. Respondents were asked if they had been admitted to hospital in the previous 12 months (yes/no).

Marital status. Respondents were asked about their current marital status. Responses of 'single', 'widowed', 'divorced', and 'separated' were given a score of one; responses of 'married', 'defacto (opposite sex)', and 'defacto (same sex)' were given a score of zero.

Income management. Respondents were asked to indicate how they managed on their available income. This item was dichotomously scored so that zero equated to responses of 'difficult some of the time', 'not too bad' or 'easy'; and a score of one indicated 'impossible' or 'difficult all of the time'.

Education. Participants were asked to indicate their highest level of completed education: no formal qualifications; School Certificate (4 years secondary school); Higher School Certificate (6 years secondary school); trade/apprenticeship; certificate/diploma; university degree; higher university degree. University and higher degree were collapsed to form a 
single category; and trade/apprenticeship and certificate/diploma were collapsed to form a single category.

Area of residence. Respondents were classified as living in urban, rural, or remote regions. ${ }^{26}$ Health insurance. Respondents were asked if they had private health insurance for hospital and/or ancillary services (eg. dental, physiotherapy etc.).

Menopause status. Women were asked whether or not they had ever had a hysterectomy or an oophorectomy, and whether or not they had menstruated in the last 12 months, or in the last three months. Respondents were also asked, 'Compared with 12 months ago, are your periods: less frequent; about the same; more frequent; changeable?’ These items were used to construct the menopause status variable that has four categories representing: surgical menopause (hysterectomy and/or oophorectomy); post-menopause (having no periods for the last 12 months, but not having had a hysterectomy/oophorectomy); perimenopause (where women had periods in the last 12 months but not the last 3 months; or had periods for the last 12 months and periods had changed in the last 12 months; or had no periods in the last 3 months and periods had changed in the last 12 months); and premenopause (where women had periods for the last 12 months and the last 3 months and periods had not changed in the previous 12 months). The 121 women that did not fit into any of the four categories were coded as missing data.

Physical and psychological health. Physical and psychological health were measured by using the Physical Component Score (PCS) and Mental Component Score (MCS) of the Medical Outcome Short Form Health Survey (SF-36). ${ }^{27}$ The SF-36 measures eight areas of health and functioning. All areas are used to calculate the PCS, with the physical health subscales (physical functioning, role-physical, and bodily pain) weighted more heavily than the remaining subscales (i.e. social functioning, general health, vitality, role emotional, mental health). ${ }^{27}$ The MCS is calculated using all subscales, with the mental health subscales (i.e. mental health, social functioning, and role emotional) weighted more heavily than the 
remaining subscales. ${ }^{27}$ Possible scores on both the PCS and MCS range from 0 - 100, with higher scores reflecting better health.

\section{Statistical analyses}

In all analyses, the sample was weighted to correct for the over-sampling of participants from rural and remote regions. Analyses were conducted using SPSS (v. 11) ${ }^{28}$. Univariate logistic regressions were used to calculate unadjusted odds ratios between domestic violence (dependent variable) and demographic, physical health status, and health service use variables.

Preliminary analyses revealed that the health service use variables were significantly associated with each other. Hence three separate multivariate logistic regression models were developed to examine associations between each health service use variable and history of domestic violence. The first model adjusted for demographic variables, the second adjusted for demographic and physical health variables, and the third model adjusted for demographic, physical health and psychological health variables.

\section{Results}

The mean age of participants was 47.73 (SD,1.48). Of the 13,978 women who responded to the question on violence, 2,165 or $15.4 \%$ indicated that they had ever lived in a violent relationship.

\section{Demographic variables and domestic violence}

Results of the univariate analyses showed that all of the demographic variables except age were significantly associated with domestic violence (see table 1). Strong associations were found between domestic violence and being single, widowed, separated or divorced, finding income management impossible or difficult, and having no health insurance. Domestic violence was also associated with education, and area of residence (table 1). 
Physical and psychological health status and domestic violence

Univariate results revealed that compared to pre-menopausal women, women who had surgical menopause, or who were post-menopausal or perimenopausal had increased odds of ever having experienced domestic violence. In addition, results for the SF-36 PCS indicated that as physical health decreased, the odds of having a history of domestic violence increased. Similarly, as psychological health decreased, the odds of having ever experienced domestic violence increased.

Table 1 about here

\section{Health service use and domestic violence}

At the univariate level, three or more family, hospital and specialist doctor consultations were associated with increased odds of having been in a violent relationship. Women who had three or more family doctor consultations in the previous year had over twice the odds of having experienced domestic violence relative to women who had not had a family doctor consultation in the previous year (unadjusted OR $=2.26,95 \% \mathrm{CI}=1.85,2.75$ ). This association remained significant after the demographic variables were included in the model (see model 1, table 2). The inclusion of both demographic and physical health status variables in the model resulted in a weaker association between three or more family doctor consultations and domestic violence $(\mathrm{OR}=1.56,95 \% \mathrm{CI}=1.25,1.95)$ (model 2, table 2). This association was weaker still when psychological health was added to the model, although the association between three or more family doctor consultations and domestic violence remained significant $(\mathrm{OR}=1.36,95 \%$ CI 1.09, 1.70).

Multivariate results for hospital and specialist doctor consultations followed a similar pattern. Having three or more consultations in the prior year remained associated with both hospital and specialist doctor consultations after adjusting for demographic and physical 
health variables, with associations being considerably weaker in the second model, than in the two previous analyses (table 2). However, when psychological health was added to the model (model 3, table 2), consultations with hospital or specialist doctors were no longer significantly associated with a history of domestic violence.

At the univariate level, women who were admitted to hospital had slightly increased odds of having experienced domestic violence relative to women who had not been admitted to hospital (unadjusted $\mathrm{OR}=1.41,95 \% \mathrm{CI}=1.23,1.58$ ). However after demographic and physical health status variables were included in the regression model, the association between hospitalisation and domestic violence was no longer significant (table 2).

Table 2 about here

\section{Discussion}

This is the first Australian study which has used a nationally representative sample of midaged women to investigate associations between health service use and history of domestic violence with simultaneous adjustment for demographic variables and health status. Women who had a higher number of consultations with health practitioners (family, hospital, and specialist doctors) also had higher odds of having experienced domestic violence. These results concur with past research reporting that women who had experienced domestic violence were over-represented in clinical populations. ${ }^{9}$ Furthermore, these results are consistent with findings that demonstrated associations between domestic violence and general practitioner consultations, ${ }^{17}$ emergency department visits, ${ }^{15}$ specialist referrals ${ }^{14}$ and hospitalisation. $^{16}$

An important strength of the study is the statistical adjustment for known confounders. Consultations with health practitioners remained significantly associated with domestic 
violence after adjusting for demographic and physical health characteristics. This result implies that women who have experienced domestic violence may be seeking consultations for reasons additional to physical health status. The contention that higher health service use may be explained by women seeking psychological support from doctors ${ }^{14,16}$ was supported by the findings, which indicated reduced relationships between doctor consultations and domestic violence when psychological health was added to the model. However, even after adjusting for physical and psychological health status there remained a significant association between family doctor consultations and domestic violence. This implies that women maybe seeking some other form of support from family doctors that cannot be explained by the poorer physical and psychological health that was experienced by women who had a history of domestic violence. Future research is needed in this area, and also to ascertain the efficacy of psychological support provided by doctors to women who have a history of domestic violence. This is an important issue, since general practitioners are facing increasing demands on their time.

Some researchers have stressed that health professionals should be trained in making domestic abuse inquiries, and, furthermore, should have information about appropriate services readily available for women who indicate that they have been experiencing domestic abuse. ${ }^{29}$ The current study supports these recommendations by demonstrating that mid-aged women who have ever experienced domestic violence are frequent users of health services and, furthermore, may be seeking consultations for psychological problems.

Domestic violence has been related to suicide attempts and psychiatric diagnoses in past research, ${ }^{30}$ and the current research found a significant association between domestic violence and poorer psychological health. Therefore, it might be expected that domestic violence would retain some association with hospital admissions after adjusting for physical 
health, to account for admissions due to psychiatric problems. However, after adjusting for physical health, the association between having ever experienced domestic violence and hospitalisation within the last 12 months fell just short of being significant. It is possible that any association between domestic violence and hospital admissions for psychiatric problems might be contingent on recency of domestic violence, which could not be assessed by the current study. Further research is required to examine the nature of any relationship between domestic violence and subsequent hospital admissions for psychiatric problems among Australian women.

It is beyond the scope of the current paper to fully discuss the implications of the findings for menopause status, however, they are worth a brief mention. Past research has shown clear relationships between domestic violence and gynaecological health problems. ${ }^{31}$ While this may explain the relationship between domestic violence and surgical menopause found in the current study, the relationship between non-surgical menopause and domestic violence is less straightforward and deserves further research.

The $15.4 \%$ prevalence rate of domestic violence in this study is lower than the $23 \%$ found by a nationally representative sample of all Australian women, ${ }^{8}$ and the $28 \%$ found by a study of mid-aged Australian women. ${ }^{10}$ Past research has indicated that use of a single item may lead to underreporting of domestic violence. ${ }^{12}$ For example, in an emergency department survey four percent of women who indicated on a single item that they had not experienced domestic violence went on to indicate that they had experienced specific acts of violence perpetrated by their partner. ${ }^{12}$ Therefore, the prevalence of domestic violence may be underestimated in the current investigation. It is difficult to know how this possible underreporting may bias our findings, and additional research is required to explore this further. 
The current study has some limitations. The investigation was cross-sectional in nature, so no temporal sequences or causal relationships can be inferred from the results. Furthermore, only limited information was gathered about the type of domestic abuse experienced, so the association between health service use and severity, frequency or duration of abuse could not be examined. Intimate partner abuse can also include one or more of a constellation of acts, including physical violence, emotional, financial, social, and sexual abuse. ${ }^{32}$ Hegarty and Roberts suggest that distinctions should also be made between sporadic occasions of violence, and systematic violence perpetrated by one partner against another. ${ }^{33}$ The current study was unable to make such distinctions between behaviours, and has defined domestic violence as ever having lived in a violent relationship with a partner or spouse. Nevertheless the results are compelling, and indicate that a history of domestic violence is associated with increased use of health services among mid-aged Australian women. Future research is needed to provide more detailed analyses of associations between the nature and frequency of specific acts of domestic abuse and the use of health services. It is possible that some reduction in associations between health service use and domestic violence may have occurred as a result of over-adjusting in the final regression model (model 3). If this is the case, then the associations between domestic violence and health service use will have been under-estimated. The longitudinal nature of the WHA study will allow us to explore these relationships further.

It is clear from this study that previously reported associations between health service use and a history of domestic violence may have failed to account adequately for physical health status as a mediating variable. However, it is necessary to tease out the extent to which both direct and indirect effects of abuse may be influencing both poorer health and health service use in midlife. Future research needs to examine more specifically how past domestic 
violence may be related to physical health status in midlife and how this, in turn, influences health service use. 


\section{Acknowledgements}

The research on which this paper is based was conducted as part of the Australian Longitudinal Study on Women's Health. The Australian Longitudinal Study on Women's Health is funded by the Australian Commonwealth Department of Health and Ageing and conducted by a team of researchers at the Universities of Newcastle and Queensland, Australia. The authors would like to thank the three anonymous reviewers for their comments on an earlier version of this paper. 


\section{References}

1. Tjaden P, Thoennes N. Prevalence and consequences of male to female and female to male intimate partner violence as measured by the National Violence Against Women Survey. Violence Against Women 2000; 6:142-61.

2. McKenzie KC, Burns RB, McCarthy EP, Freund KM. Prevalence of domestic violence in an inpatient female population. J Gen Intern Med. 1998; 13:277-79.

3. Bauer HM, Rodriguez MA, Perez-Stable EJ. Prevalence and determinants of intimate partner abuse among public hospital primary care patients. J Gen Intern Med 2000; 15:811-817.

4. Ernst AA, Nick TG, Weiss SJ, Houry D, Mills T. Domestic violence in an inner-city ED. Ann of Emerg Med 1997; 30:190-197.

5. Abbott J, Johnson R, Koziolmclain J, Lowenstein SR. Domestic violence against women - Incidence and prevalence in an emergency department population. JAMA 1995; 273:1763-1767.

6. Richardson J, Coid J, Petruckvitch A, Chung WS, Moorey S, Feder G. Identifying domestic violence: cross sectional study in primary care. BMJ 2002; 324:274-277.

7. Bradley F, Smith M, Long J, O’Dowd T. Reported frequency of domestic violence: cross sectional survey of women attending general practice. BMJ 2002; 324:271-274.

8. Australian Bureau of Statistics. Women’s Safety Australia. Canberra; 1996.

9. Mazza D, Dennerstein L, Ryan V. Physical, sexual and emotional violence against women: A general practice-based prevalence study. Med J Aust 1996; 164:14-17.

10. Mazza D, Dennerstein L, Garamszegi CV, Dudley EC. The physical, sexual and emotional violence history of middle-aged women: A community-based prevalence study. Medical J Aust 2001; 175:199-201.

11. Hegarty KL, Bush R. Prevalence and associations of partner abuse in women attending general practice: a cross-sectional survey. Aust NZJ Public Health 2002; 26:437-442.

12. de Vries Robbé M, March L, Vinen J, Horner D, \& Roberts G. Prevalence of domestic violence among patients attending a hospital emergency department. Aust NZJ Public Health 1996; 20:364-368. 
13. Roberts GL, O’Toole BI, Raphael B, Lawrence JM, Ashby R. Prevalence study of domestic violence victims in an emergency department. Ann Emerg Med 1996; 27:741-753.

14. Wisner CL, Gilmer TP, Saltzman LE, Zink TM. Intimate partner violence against women: Do victims cost health plans more? J Fam Pract 1999; 48:439-443.

15. Richardson DM, Becker BM, McGrath ME, Duffy SJ, Minugh PA, St Angelo LM. Health care use by physically and sexually abused women. Ann Intern Med 1996; $27: 138$.

16. Bergman B, Brismar B, Nordin C. Utilisation of medical care by abused women. BMJ 1992; 305:27-29.

17. Wasson JH, Jette AM, Anderson J, Johnson DJ, Nelson EC, Kilo CM. Routine, single-item screening to identify abusive relationships in women. J Fam Pract 2000; 49:1017-1022.

18. Scholle SH, Rost KM, Golding JM. Physical abuse among depressed women. J Gen Intern Med 1998; 13:607-613.

19. Tolman RM, Rosen D. Domestic violence in the lives of women receiving welfare Mental health, substance dependence, and economic well-being. Violence Against Women 2001; 7:141-158.

20. Muelleman RL, Lenaghan PA, Pakieser RA. Nonbattering presentations to the ED of women in physically abusive relationships. Am J Emerg Med 1998; 16:128-131.

21. Lown EA, Vega WA. Intimate partner violence and health: Self-assessed health, chronic health, and somatic symptoms among Mexican American women. Psychosom Med 2001; 63:352-360.

22. Heise L, Ellsberg M, Gottemoeller M. Ending violence against women. Population reports, Series L, Number 11. Baltimore: Johns Hopkins University School of Public Health, Population Information Program; 1999.

23. Lee C. Women's Health Australia: what do we know? What do we need to know? Brisbane: Australian Academic Press; 2001.

24. Brown WJ, Bryson L, Byles JE, Dobson AJ, Lee C, Mishra G, Schofield M. Women’s Health Australia: Recruitment for a national longitudinal cohort study. Women’s Health 1998; 28:23-40. 
25. Australian Bureau of Statistics. ABS Population Survey 1989 - 1990 National Health Survey Users Guide. Canberra: ABS; 1991.

26. Australian Department of Primary Industries and Energy; Australian Department of Human Services and Health. Rural, remote and metropolitan areas classification: 1991 census edition. Canberra: Australian Government Publishing Service; 1994.

27. Ware, JE, Sharebourne, CD. The MOS 36-Item Short-Form Health Survey (SF-36): 1. Conceptual framework and item selection. Medical Care 1992; 30:473-483.

28. SPSS for Windows version 11.0.1. (2001). Chicago: SPSS Inc.

29. Taket A, Nurse J, Smith K, Watson J, Shakespeare J, Lavis V, Cosgrove K, Mulley K, Feder G. Routinely asking women about domestic violence in health settings. BMJ 2003;173:363-367.

30. Kernic MA, Wolf ME, Holt VL. Rates and relative risk of hospital admission among women in violent intimate partner relationships. American Journal of Public Health 2000; 90: 1416-1420.

31. Campbell JC, Woods AB, Chouaf KL, Parker B. Reproductive health consequences of intimate partner violence. Clinical Nursing Research. 2000; 9:217-237.

32. Hegarty K, Hindmarsh ED, Gilles M. Domestic violence in Australia: definition, prevalence and nature of presentation in clinical practice. Med J Aust 2000; 173:363367.

33. Hegarty K, Roberts G. How common is domestic violence against women? The definition of partner abuse in prevalence studies. Aust NZJ Public Health 1998; 22:4954. 
Table 1: Unadjusted Odds Ratios and 95\% Confidence Intervals for the odds of having experienced domestic violence by demographic factors and physical health

History of domestic violence

\begin{tabular}{lcccc}
\cline { 3 - 4 } & $\mathrm{N}$ & $\%$ & Unadjusted OR & 95\% CI \\
\hline $\begin{array}{l}\text { Demographics } \\
\text { Age }^{\mathrm{a}}\end{array}$ & 13945 & 0.98 & $0.95,1.01$
\end{tabular}

Marital status:

Married/defacto

$11233 \quad 12 \quad 1.00$ (ref)

Not married nor defacto

2663

32

3.60

3.26, 3.98

Income management

Not impossible/difficult

$11868 \quad 13 \quad 1.00$ (ref)

Impossible/difficult

2009

29

2.75

2.46, 3.07

Education

University or higher degree

$2291 \quad 12$

1.00 (ref)

Trade/apprenticeship/cert./dip.

2716

14

1.23

1.04, 1.45

Higher school certificate

2421

14

1.21

1.02, 1.44

School certificate

4099

15

1.32

1.13, 1.53

No formal qualification

2338

22

2.09

$1.78,2.45$

Area of residence

Urban

$\begin{array}{llll}10087 & 15 & 1.00 \text { (ref) } & \\ 3460 & 17 & 1.16 & 1.04,1.29 \\ 369 & 19 & 1.32 & 1.01,1.73\end{array}$

Remote

Health insurance

Hospital and ancillary

$5827 \quad 10 \quad 1.00$ (ref)

Ancillary only

1101

15

1.60

1.33, 1.92

Hospital only

1175

10

0.92

$0.75,1.14$

None

5801

22

2.48

2.24, 2.76

Physical health

Menopause Status

Premenopausal

Perimenopause

Surgical menopause

3824

13

1.00 (ref)

3824

15

1.26

1.12, 1.42

3132

20

1.75

1.56, 1.97

Post-menopause

1198

17

1.45

1.23, 1.72

Physical health (SF-36 PCS) ${ }^{\mathrm{b}}$

13118

0.97

0.96, 0.97

Psychological health (SF-36 MCS)

13099

0.96

0.96, 0.97

Note. N's refer to the number of women who were in each category, for example, 11233 women were either married or living in a defacto relationship. Percentages refer to the percentage of women per category that had experienced domestic violence, for example, $12 \%$ of the 11233 women who were either married or living in a defacto relationship had experienced domestic violence.

a Age was a continuous variable: $\mathrm{DV}$ ever mean $=47.69, \mathrm{SD}=1.49$, DV never mean $=47.74, \mathrm{SD}=1.49$.

b The SF-36 Physical Component Score was a continuous variable: DV ever mean $=47.05, \mathrm{SD}=11.48, \mathrm{DV}$ never mean $=50.56$, $\mathrm{SD}=9.59$.

c The Sf-36 Mental Component Score was a continuous variable: DV ever mean = 46.61, SD = 11.42, DV never mean = 50.72, SD = 9.55. 
Table 2: Odds of having a history of history of domestic violence by health service use: Unadjusted; adjusted for demographics (Model 1); and adjusted for demographics and physical health status (Model 2).

Associations between history of domestic violence and health service use

\begin{tabular}{|c|c|c|c|c|c|c|}
\hline \multirow{3}{*}{$\begin{array}{l}\text { Health service } \\
\text { use previous } \\
\text { year }\end{array}$} & & & \multirow[t]{2}{*}{ Unadjusted } & \multirow{2}{*}{$\begin{array}{c}\text { Model } 1^{\mathrm{a}} \\
\text { Adjusted for } \\
\text { demographics }\end{array}$} & \multirow{2}{*}{$\begin{array}{c}\text { Model } 2^{\mathrm{b}} \\
\text { Adjusted for } \\
\text { demographics and } \\
\text { physical health } \\
\text { status }\end{array}$} & \multirow{2}{*}{$\begin{array}{c}\text { Model } 3^{\mathrm{c}} \\
\text { Adjusted for } \\
\text { demographics } \\
\text { physical and } \\
\text { psychological } \\
\text { health status }\end{array}$} \\
\hline & & & & & & \\
\hline & $\mathrm{N}$ & $\%$ & OR (95\% CI) & OR (95\% CI) & OR (95\% CI) & OR (95\% CI) \\
\hline \multicolumn{7}{|l|}{ Family doctor } \\
\hline 0 & 1159 & 11 & 1.00 (ref) & 1.00 (ref) & 1.00 (ref) & 1.00 (ref) \\
\hline $1-2$ & 8598 & 13 & $1.19(0.98,1.45)$ & $1.25(1.02,1.53)$ & $1.13(0.92,1.39)$ & $1.10(0.89,1.35)$ \\
\hline $3+$ & 4145 & 22 & $2.26(1.85,2.75)$ & $2.07(1.68,2.55)$ & $1.56(1.25,1.95)$ & $1.36(1.09,1.70)$ \\
\hline
\end{tabular}

Hospital doctor

$\begin{array}{lrrllll}0 & 11533 & 14 & 1.00(\mathrm{ref}) & 1.00(\mathrm{ref}) & 1.00(\mathrm{ref}) & 1.00 \text { (ref) } \\ 1-2 & 1509 & 20 & 1.46(1.27,1.67) & 1.21(1.05,1.41) & 1.09(0.93,1.28) & 1.04(0.89,1.22) \\ 3+ & 573 & 29 & 2.46(2.04,2.97) & 1.77(1.44,2.17) & 1.28(1.02,1.60) & 1.16(0.92,1.45)\end{array}$

Specialist

doctor

$\begin{array}{lllllll}0 & 7749 & 14 & 1.00(\mathrm{ref}) & 1.00(\mathrm{ref}) & 1.00(\mathrm{ref}) & 1.00 \text { (ref) } \\ 1-2 & 3796 & 15 & 1.09(0.98,1.22) & 1.12(1.00,1.26) & 1.05(0.93,1.19) & 1.02(0.91,1.16) \\ 3+ & 2190 & 21 & 1.68(1.49,1.90) & 1.54(1.35,1.75) & 1.23(1.07,1.43) & 1.14(0.98,1.32)\end{array}$

Admitted to hospital

$\begin{array}{lllllll}\text { No } & 11728 & 15 & 1.00 \text { (ref) } & 1.00 \text { (ref) } & 1.00 \text { (ref) } & 1.00 \text { (ref) } \\ \text { Yes } & 2222 & 20 & 1.41(1.25,1.58) & 1.36(1.20,1.54) & 1.14(0.99,1.30) & 1.10(0.96,1.26)\end{array}$

Note. N's refer to the number of women who were in each category, for example, 1159 women had no (0) consultations with family doctors in the previous year. Percentages refer to the percentage of women per category that had experienced domestic violence, for example, $11 \%$ of the 1159 women who had no family doctor consultations in the previous year had experienced domestic violence.

a Association with domestic violence after adjusting for demographic variables (i.e. age, marital status, income management, education, area, health insurance).

b Association with domestic violence after adjusting for demographic, and physical health variables (i.e. menopause status, physical health [SF-36 PCS]).

c Association with domestic violence after adjusting for demographic, physical health, and psychological health variables (i.e. SF-36 MCS). 